\title{
The Management Aspect of Psychotherapy with Aggressive Children
}

\author{
Steven Frankel, MD \\ University of Michigan Medical Center
}

\begin{abstract}
Psychotherapy with an aggressive child may require the imposition of rather firm limitations over aspects of the patient's aggressive behavior. The nature of this management strategy is determined by the individual child's psychopathology. The management aspects of the psychotherapy with two aggressive boys are illustrated in detail. In one case, stringent limitations were imposed when it was discovered that the boy's behavior was regressive and represented an effort to sadistically control people in his environment. In the other case, the behavior was initially left almost unchallenged; this boy's aggressive and delinquent behavior reflected an effort to achieve a sense of order in an inconsistent external and potentially chaotic internal environment.
\end{abstract}

\section{Introduction}

The concept "therapeutic alliance" in both child and adult psychotherapy refers to the overt and tacit agreement between patient and therapist to work together to understand the nature of the patient's difficulties [1-4]. As much as is possible, priority is given to verbalization and conceptualization as opposed to action. (Children of latency age and below are initially far less capable of achieving this ideal than are post-latency children and adults. In addition, within limits, a child's action is valued and used to provide associative information, which an adult patient provides verbally through free association. At best, a latency- or prelatency-age child develops a commitment to the therapeutic process only after a long and delicate initial phase of treatment [1] .) Frequently, however, the unconscious attitude and related behavior that a patient brings to therapy oppose this process of exploring the patient's experience. Often, that behavior has the

Dr. Frankel is Assistant Professor of Psychiatry in the Department of Psychiatry, Children's Psychiatric Hospital, University of Michigan Medical Center, Ann Arbor, Michigan 48104. 
purpose of inviting the therapist to act out a distorted or infantile relationship with the patient. Management in child psychotherapy refers to the activities and postures that are adopted by the therapist for the purpose of counteracting and preventing this counterproductive activity.

A management plan is derived from, and therefore conforms to, the (psychological) meaning of the patient's behavior and takes into consideration his or her developmental needs and particular tolerances. It is evolved as the therapist gains an understanding of the patient's behavior. Its form is unique to the patient for whom it is designed. Its description evolves and changes with the progress of the treatment.

The principle of management has clear parallels in adult psychotherapy. In work with adults, the efforts by a patient to act out in some form with the therapist, for example, by attacking him verbally or seducing him, are blocked and identified. Ultimately, an explanation for these behaviors is sought. These behaviors are considered resistances and more specifically are character or transference resistances.

A major difference between child and adult psychotherapy derives from the fact that children tend to engage in action instead of using words $[5,6]$. It follows and is well accepted that in psychotherapy with children, it is frequently necessary to set limits on a child's activity both because of the child's developmental limitations and, at times, in order to contain the acting-out of a neurotic process [7]. (The reader is referred to the following references for a more thorough discussion of the issue of action and its management in child psychotherapy and psychoanalysis: a theoretical treatment of action and acting-out $[7$, pp. 26-53; 5, pp.94-109; 6; 8]; the setting of limits in child psychotherapy and psychoanalysis [9, pp. 19-49; 7, pp. 26-53] ; the concept of a parameter and the debate about the use of parameters in work with children [10-13].) The kind of limitations that are being referred to here include the limiting of such behavior as the destruction of material, the rendering of harm to the therapist, or the leaving and running away from the office.

With most neurotic and inhibited children, limitations over action can be communicated verbally or, at most, have to be enforced by removing something temporarily from the office or play room. The situation with aggressive children, however, is quite different. The usual means of enforcing limitations are often without effect [14]. It is the thesis of this paper that with certain aggressive children, firm controls often involving the physical handling of the child or the strict imposi- 
tion of control over his or her activity may at times have to be employed. This is done when the judgment is made that the child can tolerate the interference with his or her aggressive behavior and that the behavior does not represent a bulwark against potentially disorganizing anxiety.

Discomfort with adopting a firm management posture derives from a concern that the use of such methods could lead to the acting-out with the patient of some need of his that is inappropriate or maladaptive. Of equal concern is the possibility that the therapist will act out some of his own needs with the patient and especially some attitude that has been evoked as countertransference, for example, where the patient's behavior has caused the therapist to become punitive [15]. I do not mean to imply that possibilities for inappropriate acting-out between patient and therapist are insignificant. Indeed, a therapist need always be watchful for the occurrence of such inappropriate activity. However, I wish to make the point that with certain aggressive children, the failure to impose a management strategy that could involve the use of rather stringent controls over the patient's activity may be equivalent to a sanction that a defensive or regressive acting-out on the part of the patient can be allowed to continue. Indeed, this failure is tantamount to a conspiracy with such behavior.

In discussing the notion of management in psychotherapy with aggressive children, it is important to mention the work of Redl and Wineman $[14,16]$. They identify a combined group and individual approach for work with aggressive children who show a striking degree of ego and superego deficiency. The rationale for their individual technique (life space interview) and the prescription about when and by whom it should be applied rests heavily on an understanding of the ego deficiencies of their patients and the difficulties these children have in becoming engaged in a trusting relationship. In contrast to the children treated by Redl and Wineman, the children described in this paper have better impulse regulation and seem more amenable to individual psychotherapy. At the same time, thoughtful behavior regulation and on-the-spot interviewing by key people in their environment, such as a teacher, may be of enormous benefit to these children and an important component of an integrated treatment plan.

The cases of two boys who have been seen at the University of Michigan Medical Center will be discussed. In spite of a striking initial similarity in the boys' behavior, opposite strategies were evolved for their management. The emphasis in the case examples is on the reasoning involved in formulating the individual management plans. In 
the case of Ken, who came to the hospital at 5.9 years of age, we elected to intervene drastically with his behavior. With Ed, who was initially referred for psychiatric treatment at age 5.7 and was referred to our facility after repeated treatment failures at age 9.10 , we elected to intervene much more slowly and carefully. The difference in the management approaches derived from the assessment that the fundamental psychopathology of the two boys was of a different order of magnitude. Ed was judged as less able to tolerate the anxiety that would have resulted had his behavior been curtailed suddenly. His delinquent-appearing behavior was thought to be a last-ditch effort to contain overwhelming and disorganizing anxiety.

\section{Case 1: Ken}

\section{Overview}

Ken was a patient in the Day Treatment Program at Children's Psychiatric Hospital for nine months. (The Day Treatment Program is a highly coordinated educational and psychotherapeutic program based on psychoanalytic principles. Children attend for a full school day, five days a week.) he was seen four times a week in psychotherapy by his first therapist during this time. At the end of this time, he was discharged to public school and was transferred to his present therapist. Since that time, he has been seen as an outpatient in four-times-a-week psychotherapy.

\section{Presenting Problems}

Ken was referred to our facility by his mother, because she was concerned about his rapidly worsening rebellious behavior. Typically, Mrs. U would tell Ken that he was forbidden to play in a certain area or forbidden to cross the street. Ken would soon be found playing in that area or crossing that street. In addition, there had been recent episogdes of stealing by him and threats to do things that could have been dangerous to himself. For example, on one occasion, he threatened to run in front of a car, and on another occasion he took a butcher knife to school with him. Mrs. U had also become aware that neither rewards nor punish. ments seemed to work with Ken. In fact, it was clear that at times Ken seemed to enjoy getting caught and even being disciplined. For example, on several occasions when he had caused some disturbance at school, he was reported to have seemed pleased about getting caught and punished.

Mrs. U's sense of helplessness needs to be emphasized. It was clearly this sense, as well as concern for her child, that motivated her to seek treatment for Ken. At the time of referral, her efforts to regulate her son seemed to vary wildly. At times, she would become extraordinarily angry and punitive. At other times, she attempted to bribe him or manipulate him into conforming by providing an excess of physical affection or excessive adultlike openness or by yielding to his demands and giving him the material things he was asking for. 


\section{Family and Developmental History}

Ken's early life was characterized by the vicissitudes in his parents' relationship. Separation finally occurred when Ken was 3.9 years of age, and divorce came when he was 4.2 years. Mrs. $U$ had been dominated by her husband from the time that they were married, two years prior to her pregnancy with Ken. This first caused her to become severely depressed, but when Ken was about 6 months old, she changed and became increasingly vindictive. In response to this, her husband's aggressive behavior escalated. Apparently, he increased his drinking, stayed away from home more, and eventually, soon after his wife announced her intention of separating from him and locked him out of the house, he resorted to violence, on at least one occasion breaking down the door and then beating his wife.

On a superficial reading, Ken often served to compensate his mother for her troubles with her husband. In fact, she looked to him from the beginning as a "very special child" and felt implicitly that he would somehow save her from her miserable existence. Missing from this picture, however, is the fact of the mother's not infrequent periods of emotional withdrawal and, at other times, reactive or displaced anger toward Ken.

Ken's intellectual and especially verbal development were precocious and are seen as an effort to adapt to his mother's periods of disinterest and depression. By his second year, there was already an "adult quality" to the way he related to people, and he was successful in using this to interest and engage his mother.

Ken's early developmental difficulties complemented Mrs. U's depression and her sense of lack of control over her life during his early years. Ken's first two years were characterized by what Mrs. U called his insatiable demands for food. This resulted in pitched battles in which Mrs. $U$ tried to assert control over his eating and later his scavenging for food. Between 24 and 36 months, there was another vigorous period of struggle over toilet training. Mrs. U personalized Ken's resistance to her efforts and treated them as if they were an intended assault on her.

\section{First Year of Treatment}

Our initial experience with Ken repeated the experience of his mother and the school he attended before ours. He was characterized as manipulative in that he knew how to play upon people's emotions to gain the things that he wanted. For example, he could act sweetly if he wanted some material object that was in the possession of one of his counselors or teachers. At the same time, this behavior was interlaced with the provocativeness that the mother had reported. For example, Ken would take things that he was prohibited from taking, would go places where he was not supposed to go, or would start a fight as soon as his teacher's back was turned. In other words, intervention into his behavior pattern generally met with the same slipperiness that had been reported prior to his admission to our facility. He might comply superficially, but he would retum to the behavior as soon as there was a chance to do so. At times, he would put up a fight, but it was always observed that there was a lack of real feeling in his complaints. People always felt that deep in his mind, Ken was simply planning to return to his earlier delinquent activity as soon as the pressure was lifted. At times, it was observed that Ken seemed to invite being caught. That is, he would do something 
openly that he was not supposed to do and would leave evidence of his misdeeds around to be discovered. However, these events had the strange quality of producing pleasure in him rather than relief. This was recognized but not really understood by us yet. At the same time, kindness also had little effect on Ken. At worst, he seemed to treat the person who was kind to him as a sort of sucker. He would simply make things worse for that person. At best, he simply got what he wanted and felt no sense of responsibility or indebtedness to the person who had been good to him.

Essentially, then, Ken appeared to be a young, but already intractable, sociopath. He was manipulative and cunning, and provocative to boot. He was seen as having almost no emotional investment in people. That is, people seemed mainly to serve certain functions for him. In addition to all of this, he was seen as bright, and it was felt that he utilized his brightness in furthering his pathological ends.

Naturally, a lot was learned about Ken in the first year, but by the year's end, those who worked well with Ken were painfully aware of their inability to influence him. There seemed to be some missing link in their understanding of him. At the same time, it was thought possible that his behavior was not amenable to influence.

It was my impression that the stance taken in therapy and in the milieu during this period clearly recognized the need for Ken to be controlled but assumed that his behavior (which was thought to reflect a regression to a variety of concerns and behaviors associated with the oral phase of development) was for the most part reactive to perceived deprivation and that he could be appealed to primarily by demonstrated concern and investment. As a result, Ken was variably controlled and disciplined (in the milieu) according to his behavior. In therapy, for example, he was forbidden to break toys, toys would not be replaced once he broke them, and his therapist made some attempt to stop him when he insisted on leaving the room. At the same time, any fantasy play was welcomed with the hope that the information it contained could be used interpretively in the treatment.

\section{Transfer and Reformulation}

At the end of the year, Ken's therapist left and Ken was transferred to his new therapist. At this time, a considerable amount of reassessment was possible, and new information could accrue through observing Ken's reaction to the change of therapists and his impending discharge from our program and return to public school.

In his new therapy, Ken continued to act as he had in the past. However, things were somewhat accentuated, and this was explained on the basis of the loss of his first therapist and the impending loss of the day treatment facility. Once Ken found out that his new therapist would not be giving him the many "new toys" he had hoped for, he began to treat the new therapist with disdain. In fact, he seemed to get some pleasure out of repelling the new therapist's efforts to engage him. For example, it was typical of Ken to play for the first half of his session. At this point, when the therapist was just becoming convinced that he had engaged him, Ken would suddenly start acting in a provocative manner. He would pretend to begin to break something or deliberately make a mark on the wall, and soon he would be demanding to be let out of the room. When 
this was disallowed. Ken might kick the table or some chairs and begin to tip things over. He continued this behavior in spite of the therapist's efforts to identify the meaning of the behavior with Ken, and he seemed to enjoy the therapist's helplessness.

Indeed, Ken was showing some reaction to the impending and already incurred losses. However, at the same time, his behavior with his new therapist was exactly the same, albeit somewhat condensed and exaggerated, as it had been with his workers in the past. In fact, it was the shallowness of Ken's reaction to his first therapist's departure that was most impressive. After the first two weeks, it was impossible to discern anything in Ken's productions that could be specifically tied to what could be called a deep attachment to his first therapist. It was in part the second therapist's inability to affect Ken, and Ken's demonstrated deficit in what could be considered a true emotional relationship with his first therapist, that led Ken's second therapist to the conclusion that a reformulation was necessary and with this a modification in the form of intervention. There was a sense that under current conditions, no real therapy could take place.

Several pieces of information were used to arrive at a new formulation. This formulation held that Ken's typical behavior was essentially sadistic in nature. Ken secretly saw himself as a tough, mean guy and was proud of that image. His behavior had the aim of engaging others by causing them to become upset. In this way, Ken would exert a kind of omnipotent control over people in his environment, that is, he made them react and made himself impressive to them. In this psychological context, punishments and discipline were welcomed by Ken because they amounted to recognition. Kindness met with disdain and escalating sadism.

It was clear also that the sadism was easy to overlook. It could be identified only through careful attention to the process of Ken's interactions. The content was deceptive, since Ken was skilled at making attractive verbal appeals that made him appear innocent and often childlike. Simultaneously, Ken would be getting immense pleasure out of pulling the wool over his victims' eyes and at times setting them up for some foul play.

The essential feature of this new formulation was to identify that under the present approach to management, regardless of the posture Ken's workers took toward him, be it in the direction of kindness or firmness, they were always conspiring in an interaction experienced sadomasochistically by Ken. That is, Ken was always of the opinion that essentially he was engaged in a power struggle, in which he could ultimately succeed in controlling his environment by provoking and thereby upsetting the people in it.

The new formulation was arrived at by using information from several sources. To begin with, we had become aware of the enormous impact Ken was having on both the staff and his therapist through his ability to make them feel upset and helpless. This had to be accounted for. A second source of information was Ken's reaction to kindness. If the original formulation had been correct, we would have expected that at worst Ken would be made uncomfortable by gestures of concern and kindness. We would not have expected him to become more ruthless and, essentially, treat the person who was attempting to benefit him as if he were a "sucker."

A third piece of information was derived from Ken's play. Typical of his sessions was a game in which six vehicles would get together and pick on a newcomer. The vehicles were part of a gang. They would entice the newcomer into think- 
ing that he was welcome. As soon as he believed them and became excited about the possibility that he could play with them, they would turn against him. They would beat him brutally and with great glee would "burn" this vehicle. The burning always had as its accompaniment the sound of flatus. This play was repeated over and over again, and the exclusion and hurting always seemed to give Ken pleasure. Our assumption was that in doing this, Ken was essentially turning passive into active. It was he who must have experienced some sense of exclusion earlier in his life and he who anticipated it now. As a result, in defense, he ganged up and made sure that the opposite happened: the new vehicle, the outsider, was treated sadistically. It is worth adding that this theme in Ken's play had a direct correlation with Ken's fantasies about anal functioning. Ken's vehicles were strong and formidable. They flew through the air, as did Ken's hero, Evel Knievel. At times, their fuel would be depleted. More important, their tail pipes could get "clogged up." He engaged in long surgical maneuvers to clear the tail pipes of disabled vehicles. When they were clear, they could then reengage in the act in which they would "burn" the newcomer, accompanied by flatus-type sounds.

Finally, a genetic explanation emerged that seemed to explain Ken's choice of behavior. It was known that Mrs. U's reaction to feeling degraded by men was to become enraged and treat them vindictively. Both Ken and his father had been. the object of Mrs. U's wrath on numerous occasions. It was known that Ken's father had responded to his wife's anger by escalating his rage and engaging in what sounded like sadistic retaliatory behavior. He would provoke and degrade her even further. By doing this, he could whip her into a frenzy and thereby recover his control over her. It was postulated that Ken's sadistic behavior had the same objective and might even have represented an identification with his father's behavior. It occurred in response to perceived disinterest or negativity by the mother, and it was intended to reengage and control her. It was exquisitely successful in achieving its aim.

\section{Intervention}

With this information, it was possible to formulate a new management strategy. The therapist, and indeed everyone else in Ken's life, would have to array themselves so they could not be sadistically abused by him. That is, they would have to undercut the feeling of power and control that his sadistic activities provided for him, while at the same time of fering him the possibility of a relationship on other terms. Specifically, this meant that when Ken began to act up in the treatment, he would have to be physically restrained. At times, this necessitated forcefully putting him into a chair; at other times, carrying him to the therapy room. This was always done in a way that would be unpleasant to Ken. It was also done with an explanation that his original effort was understood as intended to upset the therapist, that indeed he could not upset the therapist, and that the therapist was in control. He was reassured that it would be okay to express verbally any feelings toward the therapist.

A similar approach was taken toward Ken's manipulations and dishonesty. It was made clear to Ken that his manipulations were understood. For a period of time, no statement, expression of affect, or action was accepted on face value. Instead, the therapist repeatedly informed Ken that he (the therapist) would have to sort out what he could trust and what he could not trust. As the therapist became more attuned to Ken and could identify his insincerity when it oc- 
curred and as Ken became less manipulative, this global posture was dropped. At this point, when a manipulation was discovered, it was swiftly identified as such and in language that approximated Ken's own. For example, Ken was often told to "cut the crap," and, as time went on, the label "baloney-bullshit layer" (called a layer because it obscured Ken's real self) was adopted to identify this kind of behavior.

A similar attitude was taken toward Ken's play. At times, his wish to play reflected a callous disregard of some piece of sadistic acting-out that had occurred in therapy or elsewhere. He simply wanted to play, did not want to be bothered to talk or think about what he had done, and got additional pleasure in forcing the therapist to let him do what he wanted. At these times, the therapist took the stance of preventing Ken's play and insisting that the play would be discontinued until Ken could discuss his acting-up in a way that seemed genuine.

At this point in the treatment, it was useless to try to explore and clarify the precipitants and underlying motives for Ken's behavior with him, for example, someone's absence or rage at being deprived of a privilege by his mother. He was not in a position to hear or use these remarks. (It was also useless to work interpretively in the displacement using Ken's play, since the play itself, e.g., the sadistic treatment of a strange car, represented primarily an outlet for sadism about which he felt little conflict.) Later, when the sadistic behavior occurred more sporadically and when a semblance of a treatment alliance developed, these interventions became useful. Early in the treatment, the most useful clarifying remarks were those aimed at the reality-testing function of the ego. Typically, these identified the inefficiency of Ken's behavior in gaining the kind of attention he wanted. He was reminded that he really did want people to like him and to be his friends, but that his behavior produced the opposite result. It made people dislike him and want less to do with him. In addition, this kind of statement was used by the therapist as the explanation for his stringent control of Ken's provocation and manipulation: "After all, what kind of helper would I be if I allowed you to continue to behave in a way which only makes things more miserable for you in the end?"

It was also considered necessary to coordinate this effort with Ken's environment. It was felt that if Ken had just one sector of his life to continue to act out this distorted relationship, he would continue to do it. In a sense, it was necessary to shut off completely Ken's access to the acting-out of his sadism. Specifically, Ken's mother and teacher were quickly educated to the meaning of Ken's actions and engaged in the effort to impose consistent and systematic limitations. Close communication among all parties was encouraged and maintained. Problems reported from home and school were routinely brought up in therapy session. At times, in fact, when Ken seemed to be acting out one form of behavior in one sector of his life (e.g., aggression with his mother) and another form of behavior in another sector (e.g., good behavior in his therapy), a liaison between the two sectors of his life was arranged. For example, on the occasions that were mentioned, Ken, the therapist, and Ken's mother would all meet together. The message to Ken was that all of his behavior was important. The sadistic behavior acted out in one sector could not be isolated from sadistic behavior acted out in another sector.

At all times, those involved in the management of Ken, in spite of the manifest severity in their regulation of his behavior, offered him the possibility of a new kind of relationship. They let him know that if he were straightforward and 
genuine in his communication, he would be listened to. At the same time, their heightened control over Ken's actions removed any possible gain from continued acting-out. He could no longer upset and provoke. Increasingly, people "knew his game" and could respond to it in a controlled and forceful way.

It should be made clear, as well, that Ken was always encouraged to express what he was feeling in words and to identify and explore the reasons for his feelings. Psychotherapy was repeatedly identified as a time and place where this might occur.

\section{Results}

As the plan swung into action, Ken reacted initially with disbelief. Consequently, his provocations escalated over the next several weeks, seemingly in an effort to discern whether we were serious about the position that we were taking. As the provocative behavior began to wane, several interesting changes began to occur. First, after about three months, Ken began to lose interest in sadistic play. Instead of using his vehicles to mutilate and burn outsiders, Ken had the vehicles begin to congeal into a cooperative and coherent group. The main activity became progressively to fly through the air and to do stunts. The aim changed from a discharge of aggressive energy to an attempt to show off for the therapist. The therapist's position of observer was not unlike that of a proud father watching his son engage in skillful physical activity. At this point, after about four months, the need to control Ken lessened. Shortly after this, at about five months, a report from the school confirmed that Ken's behavior was changing. He had transformed into a child who was a bit mischievous but otherwise really indistinguishable from the other children. Most impressive, he had begun to make friends and was keeping them.

An interesting corollary to these changes was the appearance of a new behavior at the time when Ken in our earlier sessions customarily attempted to provoke the therapist and to break free from the room. Now Ken would tell the therapist that he had to have a "b.m." He would say this with pride and would enjoy having the therapist accompany him to the bathroom. Ken confided that he sometimes saved up his b.m. so that he could go in tremendous quantity. There was very little aggressive acting-out around this activity. Rather, Ken seemed to feel like the car with the clear and functioning tail pipe. That is, his ability to regulate his b.m. seemed to make him feel good, powerful, and confident.

Accompanying this seemingly new attitude toward people and this new view of himself with regard to people, that is, as someone to be admired, Ken began to develop anxiety. A theme of robbers coming in the night emerged and was played out in several sessions. Sometimes there was fighting in his nighttime scenes. Once the image of a bloody woman was evoked. On another occasion, he had a dream in which a boy's nose filled with blood and grew; then, when he went to school, his schoolmates made fun of him. There were also several fantasy games in which Ken fought with and injured males (or, in the displacement, masculine vehicles) only to find himself in danger of retaliation. These themes seemed to relate to Ken's sexual interests, in particular to his curiosity and concern about his mother's sexual behavior with her new male companion and a growing conflicted attitude about these interests. It was difficult for Ken to talk about these issues at this point. He became reticent and at times embarrassed when they were raised. He denied any interest in sexuality and, in fact, on several occasions his 
puppet told the therapist that he did not believe in sex. This denial was rather amusing when taken in the context of Ken's earlier bravado.

It is possible to make some inferences about the reasons for Ken's changes. To begin with, it seems that the new management stance prevented Ken from continuing to act out in a regressive way, removed any incentives for him to act out in this way, and provided the possibility of a new, more gratifying mode of interaction as an alternative. However, this is somewhat abstract. In essence, it appeared that Ken was provided with an alternative to his behavior. Our constant vigilance and the imposition of strict and consistent limitations were apparently experienced by Ken as reassuring. In themselves, they provided an alternative to the desperate efforts that Ken used to engage objects through his earlier sadistic behavior. That is, our efforts to control Ken and to read him accurately were experienced by him as our being concerned about him.

Further, as Ken was prevented from acting out his impulses, these impulses became increasingly threatening to him, that is, conflictual. This resulted both because of the changed attitude of the external world (when he acts up, he is disciplined now) and because of newly evolved inner prohibitions (as he increasingly valued the love of an object, his impulses became less acceptable on the basis of their potential destructive effect on the relationship).

The second major area of effort in the work was Ken's mother. Weekly meetings with her allowed us to identify her sense of vulnerability to degradation by males, including Ken. She accepted this freely and worked successfully to strengthen her position with regard to Ken. This enabled her to take a greater distance from Ken on all fronts and to deal with him more firmly and consistently.

\section{Case 2: Ed}

\section{Overview}

Ed has been seen in three-times-a-week psychotherapy since his admission to our inpatient service about a year ago at age 9.10 years. Our decision about management in Ed's case contrasts with our decision in Ken's case in that we elected to intervene very little in Ed's behavior. Ed was initially referred for treatment at age 5.7 by the school system. His behavior was unmanageable and apparently unresponsive to their efforts. He was unable to concentrate on his schoolwork. He was easily distracted and was prone to act. In addition, he tended to be unrealistic about his abilities, often claiming to be able to do things that were far beyond the expectation for someone of his age. At other times, he acted in a demanding and provocative way. The image he provided of himself included the following characteristics: he was powerful and experienced, he was cunning and daring, and he could get away with things in the manner of an experienced criminal. Consistent with the last aspect of his identity, he was often implicated in small delinquencies, including minor thefts.

Ed's behavior and lack of responsiveness to those who attempted to intervene ultimately brought an angry and punitive response. They resulted in his termination from a variety of school settings. Further, the inability and unwillingness of his parents to cooperate resulted in the failure of several attempts at psychotherapy. His referral to our hospital after having been out of school off and on for three years represented a last-ditch effort to intervene in a seemingly impossible situation. 
Our initial understanding of Ed's parents and their effect on Ed's development was as follows. Both Mr. and Mrs. F behaved in a confused and vacillating manner. Mrs. F, for example, was capable of making a decision to go on a major trip at a moment's notice. Or either Mr. or Mrs. F would suddenly hit on a plan to buy an expensive item, such as a boat. These plans could be dropped as easily as they were formulated. From what we could tell, Mr. and Mrs. F's method of dealing with their children had much the same character. At one moment, Ed was given the role of companion for his mother on a remarkable trip that she suddenly planned for both of them. The following week, Mrs. F became detached and self-absorbed and was thinking of sending her son to a military school. In short, Mrs. F's thinking was characterized by self-absorption and grandiosity, and her interests and her ideas vacillated markedly from moment to moment. As part of this, her perception and use of her son also fluctuated and reflected her current interest and mood. For the most part, she dealt with him as having needs that reflected her own or as having a function that in some way would help her realize a current inclination. Such was the background of Ed's entire development.

To complicate this already confused and unempathic setting, the Fs experienced a major traumatic event when Ed was $5 \frac{1 / 2}{2}$ years old. At that time, Ed's older brother, who had been sick for only a year, died. This was also the time of Ed's first separation from his family, through attendance at school. These two events in Ed's life were complicated by the reaction of his parents to his brother's death. They became even more distraught and disorganized than they had been previously. They also were inclined to displace their feelings about the older son and his death onto Ed. This further accentuated their already significant failure to be able to empathize with Ed's needs and feelings. At times, they clung even more closely to Ed, and his mother, in particular, used him to replace her older son. At other times, when Ed's behavior seemed to remind them of the stress they had endured, they became even more extrusive with Ed than they had been in the past. For example, on several occasions, they devised plans to send Ed away to a boarding school.

\section{Initial Period of Treatment}

We elected to be tentative in the beginning with Ed. We felt we needed to get a better reading on the nature and meaning of his boastful and possibly delinquent behavior. Furthermore, we had little appreciation for the nature of his underlying psychopathology. It was under the microscope of the psychotherapy that we began to get the information that we needed. It was here that Ed showed his greatest discomfort. In a group or in the pool room, Ed could at least engage in some effort to impress that seemed coherent. He billed himself as a cool guy, capable of successfully carrying off all kinds of crimes. He managed to capture the attention of his peer group and thereby to keep them at an emotional distance from himself. However, in close proximity to his therapist, it was noted that his coherent bravado gave way. Under this circumstance, he became anxious and disorganized, and he needed to withdraw and defend himself through the building of tinker toy forts. His therapist also noticed efforts to assert control over their schedule and play. Ed seemed to be defending himself against unanticipated changes. He seemed extraordinarily anxious and distrustful and implied that he expected the therapist to be inconsistent and disappointing. This made particular sense in light of what we knew about his parents. That is, his expecta- 
tions of the therapist seemed to reflect the kind of relationship he had experienced with his parents.

\section{Formulation}

As we grew to understand Ed, we arrived at the following formulation. Ed's boastfulness and delinquencies were felt to have several purposes. To begin with, they enabled him to keep a distance from people. Apparently, close emotional proximity was threatening to Ed. Second, they provided a kind of identity for Ed. The confusion within which he had grown and his parents' changing investment in him may have prevented the development of a stable sense of self. Therefore, this "pseudo-identity" enabled Ed to deal with a changeable and confusing environment and a confused inner state. We wondered further about the depth of Ed's disturbance. It was impossible to be certain of this at that point in our work, but we recognized the possibility that his defensive behavior could mask a disturbance of borderline or psychotic proportions.

\section{Intervention}

In contrast to our decision in Ken's case, we decided that Ed's defenses were in certain ways essential to him. According to our formulation, they represented his most organized and, therefore, his most adaptive level of functioning at the time. Our decision, therefore, was to allow Ed to retain his defensive behavior. This would help Ed to continue an optimal amount of distancing from threatening figures and events in his environment. At the same time, we began a strenuous effort to demonstrate and identify for Ed the consistency of his new environment and of the new figures in his life. As part of this, we insisted that an emphasis be put on the consistency of his workers, for example, in their maintaining of schedules, a constant physical environment, etc. In his therapy, it seemed useful to restrict Ed to spending his time in the therapy room in spite of his energetic protestations. Together with this strategy, we were slowly able to identify the broad meaning of Ed's behavior to him. We were able to let him know that we recognized that he anticipated that we could not be trusted. We worked to identify the specific nature of his distrust and contrasted it with our real intentions. During this period, we also identified Ed's exquisite sensitivity to change, and we were able to begin to link it to its origins in his parents' unpredictable behavior.

\section{Results}

Our results contrasted sharply with those of earlier efforts to treat Ed. In the earlier efforts, attempts had been made essentially to control and discipline Ed. From Ed's point of view, this meant an abrupt challenge to his system of defensive distancing. The effect was simply to put stress on Ed and to stimulate defensive efforts that were more extreme and desperate.

His response to our efforts was quite the opposite. Within six months, Ed was noted to be relaxing progressively. His boasting diminished. He became more realistically engaged in the activities of the hospital. Most significant, he began to develop trust in his workers and especially in his therapist. He was increasingly 
able to reveal to them his confusion and anxiety and to deal with them as potentially helpful allies.

\section{Discussion}

In designing a management strategy, the primary task is to become aware of the neurotic aspects of the patient's behavior that if allowed to persist unchallenged would constitute a resistance to the treatment and would amount in many cases to a mutual acting-out between therapist and patient. Management refers to the deliberate effort that the therapist makes to avoid such overt or subtle interactions and to identify and obstruct such actions on the part of the patient when they seem to be working counter to therapeutic objectives.

A second set of considerations in formulating a management plan has to do with a child's need for auxiliary ego and superego support. These functions may be absent or faulty in children on the basis of their developmental status or as a result of their regressive or defensive posture $[7,13]$. For example, initially, Ken's superego was faulty. He both enjoyed the efforts made by others to discipline him and showed little remorse or concern about the effect of his behavior on others. Further, his judgment (ego) was faulty, and he was unable to plan or predict the truly painful consequences of his actions. The therapist, as part of his management strategy, provided and in a sense taught these operations. He interfered with Ken's sadistic behavior and repeatedly pointed out its consequences for him.

A final component of management is the effort to engage the child on a less defended and more introspective level. Without this component, the obstructive and educative functions would fail in their objective. There would be little inducement for the child to give up his or her original behavior. Related to this activity is the therapist's empathic response to the patient's distress and his interest in helping the patient to overcome this through helping him gain an understanding of it. Further, dimensions of the real relationship are involved here. The therapist offers features of a real relationship to the child but on a level that is free from neurotic or otherwise distorted features [7, $13,17]$.

The above consideration applies to children whose defensive behavior is not critical to their overall psychological integrity. In many cases, such as with Ken, the behavior in question is regressive, and the basis for a more advanced level of interaction exists within the patient. This capability usually can be identified with certainty only after the management technique is interposed. It is identified by the 
nature and speed of change as it occurs. For example, Ken rather quickly reverted from a sadistic stance associated with anal level psychology to an exhibitionistic stance associated with the phallic level. The contrasting situation has already been identified and illustrated by the case of Ed. If a child is acutely vulnerable or if his pathological behavior represents his highest and best-defended level of operation, then a supportive stance is indicated. Here, the patient's need to behave in the manner in which he presents himself should be respected. The patient's behavior is curtailed mainly when it might lead to circumstances that themselves would raise his anxiety level, for example, destructive behavior directed toward the child's own person or toward others. In conjunction, an approach that aims at creating safety from underlying anxieties and simultaneously strengthening relevant ego functions is utilized.

The formulation and application of a management posture has been illustrated in two cases of aggressive boys. In Ken's case, it appeared that we were dealing with a child whose behavior was regressed. Under the stress of his mother's reactions, he had regressed from a wish to be admired on a phallic and Oedipal level to a need to gain recognition through force, that is, through a modality associated with the anal-sadistic phase of development. Ken's ego functioning also seemed potentially quite good, that is, he was capable of sustained and complex attention to situations and people. In short, it was felt that Ken was capable of functioning on a higher level in his object relations, and in his life in general, and that our restriction of his "acting-out" behavior would optimize the possibility of his reverting to this level of functioning and ultimately developing beyond it.

The significance of Ed's behavior, on the other hand, was quite opposite to Ken's. Ed's development had been arrested at a relatively early stage, at which the issues of trust and the sense of self-independence of objects were not yet crystallized. When an object acted unpredictably, Ed, if undefended, experienced panic equivalent to the loss of a coherent orientation with reference both to himself and to objects. Obviously, our goals with Ed needed to be different from our goals with Ken. We needed to respect Ed's adaptive use of a delinquent pseudo-identity, with the expectation that he could safely shed this protective device only as his trust in objects and simultaneously his sense of identity were strengthened. Our efforts were therefore mainly directed toward these ends.

Finally, it should be emphasized that an infinite variety of management plans can be conceived of, each constructed with reference to the dimensions of aparticular psychopathological constellation that 
threatens to be acted out within the therapeutic relationship. For example, aggressive behavior need not reflect the raw expression of sadism, as it did in Ken's case. Alternatively, it might represent a neurotic bid for punishment or the reenactment of an earlier traumatic experience. In either case, the hallmark of a management stance would be restraint, and its specifics would correspond to the descriptive nature of the patient's concerns. (Indeed, imposing too much control on these patients will amount to conspiring with the pathology and may have its basis in countertransference feelings.) For example, if a patient repeatedly breaks items because of an unconscious wish to be punished, it might be useful to place some limit on the patient's access to valuable items while at the same time acting in a way that conveys to the patient the therapist's benign and concerned attitude toward his or her behavior. In summary, the therapist needs to understand the patient's neurotic expectations of him and to arrange the therapy situation and behave in such a way that he minimizes the possibilities of confirming these expectations.

\section{References}

1. Frankl L, Hellman I: The ego's participation in the therapeutic alliance. Int J Psychoanal 43:333-337, 1962.

2. Keith C: The therapeutic alliance in child psychotherapy. J Am Acad Child Psychiatry 7:31-43,1968.

3. Novick J: The vicissitudes of the "working alliance" in the analysis of a latency age girl. Psychoanal Study Child 25:231-256, 1970.

4. Sandler J, Dare C, Holder A: The Patient and the Analyst. New York, International Universities Press, 1973.

5. Freud A: Acting out, 1968. In The Writings of Anna Freud (Vol 7). New York, International Universities Press, 1974, 94-109.

6. Stein M: Acting out as a character trait. Psychoanal Study Child 28:347$364,1973$.

7. Freud A: Normality and pathology in childhood; Assessments of development. In The Writings of Anna Freud (Vol 6). New York, International Universities Press, 1974, 26-53.

8. Sandler J, Kennedy H, Tyson R: Discussions of transference: The treatment situation and technique in child analysis. Psychoanal Study Child 30:375$409,1975$.

9. Freud A: Ego and the mechanisms of defense, 1936. In The Writings of Anna Freud (Vol 2). New York, International Universities Press, 1974, 22 68.

10. Eissler K: The effect of the structure of the ego on psychoanalytic technique. J Am Psychoanal Assoc 1:104-143, 1953.

11. Weiss S: Parameters in child analysis. J Am Psychoanal Assoc 12:587-599, 1964.

12. Coppolillo $\mathrm{H}$ : A technical consideration in child psychoanalysis and child psychotherapy. J Am Acad Child Psychiatry 8:411-435, 1969.

13. Maenchen A: On the technique of child analysis in relation to stages of development. Psychoanal Study Child 25:175-208, 1970. 
14. Redl F, Wineman D: Controls from within. Techniques for the Treatment of the Aggressive Child. New York, Free Press, 1952.

15. King C: Countertransference and counterexperience in the treatment of violence-prone youth. Am J Orthopsychiatry 46:43-53, 1976.

16. Wineman D, Redl F: Children Who Hate. Glencoe, Ill, Free Press, 1951.

17. Freud A: Four lectures on child analysis: The methods of child analysis, 1927. In The Writings of Anna Freud (Vol 1). New York, International Universities Press, 1974, 19-49. 